\title{
Density dependent foraging of sea urchins in shallow subtidal reefs on the west coast of Italy (western Mediterranean)
}

\author{
Lisandro Benedetti-Cecchi*, Fabio Bulleri, Francesco Cinelli \\ Dipartimento di Scienze dell'Uomo e dell'Ambiente, via A. Volta 6, I-56126 Pisa, Italy
}

\begin{abstract}
The ecological role of the sea urchins Paracentrotus lividus and Arbacia Lixula was examined in shallow subtidal reefs on the west coast of Italy from December 1994 to July 1996. The density of sea urchins was manipulated experimentally in patches of vertical substrata without erect algae. The following propositions were examined: (1) that sea urchins were responsible for the persistence of patches of bare rock and encrusting corallines in shallow subtidal habitats, (2) that their effects were density dependent, and (3) that these effects were consistent in time. The experimental manipulations consisted of 3 replicate patches randomly assigned to one of the following treatments: (1) $0 \times$ (total removals), (2) $0.5 \times(50 \%$ of the average density found in untouched patches). (3) $1 \times$ (untouched patches), and (4) $2 \times(200 \%$ of the average density found in the untouched patches). The removal of sea urchins significantly increased the coverage of the filamentous and fleshy algae in permanent plots, and these effects were consistent over time. In contrast, grazing had no effect on the encrusting corallines, Peyssonnelia spp. and invertebrates (barnacles, bryozoans and limpets). The response of the filamentous algae was proportional to the density of sea urchins, with percent cover values in the $0.5 x$ treatment being intermediate to those observed in the $0 x$ and $1 \times$ treatments. Conversely, the response of the fleshy algae was non-linear: only when sea urchins were totaly removed did the coverage of these plants increase significantly. Doubling the density of sea urchins significantly increased the erosion of the margins of the patches, while their removal caused no change along the perimeter. In general, there was considerable variability from patch to patch in the abundance of most of the response variables analysed, while temporal changes were less important. The results show that sea urchins can have significant but variable effects on vertical patches of barren habitat; alternative explanations are suggested to account for the persistence of these patches despite the removal of grazers.
\end{abstract}

KEY WORDS: Temperate reefs - Subtidal Sea urchins - Paracentrotus - Arbacia - Grazing - Density dependence Spatial heterogeneity

\section{INTRODUCTION}

Sea urchins are among the most efficient grazers in benthic marine habitats and their ecological importance has been demonstrated in different systems and at different latitudes (Lawrence 1975, Sousa et al. 1981, Hawkins \& Hartnoll 1983). These herbivores have the potential to affect the structure of biological assemblages by removing canopies of algae or by preventing their establishment (Duggins 1980, Chapman 1981, Andrew \& Choat 1982, Himmelman et al. 1983,

•E-mail; bencecc@discat.unipi.it
Dean et al. 1984, Witman 1987, Andrew \& Underwood 1993). They may also have indirect effects by providing and maintaining patches of cleared space where other organisms can settle and survive (Sammarco 1980, Fletcher 1987).

There is evidence indicating that grazing by sea urchins may be spatially and temporally variable (Elner \& Vadas 1990, Andrew 1993, Hagen 1995). For example, sea urchins can transform kelp forests into barren habitats if they are organized in fronts that actively search for food. In contrast, urchins may have a minor impact if they live in crevices and forage on drifting algae. What determines the shift from one foraging behaviour to the other is not fully understood, 
but seems to be a response to a complex set of physical and biological variables including size of populations, availability of food, presence of predators and water motion (Vance \& Schmitt 1979, Cowen et al. 1982, Carpenter 1984, Johnson \& Mann 1988, Scheibling \& Hamm 1991, Sala \& Zabala 1996). In addition, the availability and spatial arrangement of refuges can have important effects on the patterns of foraging at small spatial scales, both in subtidal habitats and in littoral rock pools (Andrew 1993, Benedetti-Cecchi \& Cinelli 1995).

Beyond local changes in the density and behaviour of sea urchins, the consistency of the impact of these grazers may also depend on the background of natural variation against which their effect is evaluated. A common approach used to investigate the effect of sea urchins is to compare the patterns of distribution and abundance of potentially impacted populations in areas where urchins have been removed or added with those occurring in untouched areas. The effects of these manipulations may appear consistent in space and time for populations that recruit continuously during the experiment and are distributed homogeneously at the study site, but are unmeasurable or ecologically unimportant if the populations have heterogeneous patterns of recruitment and distribution (e.g. Prince 1995). Therefore, a full appreciation of the ecological role of sea urchins requires knowledge of the effects of density of these populations, an evaluation of the consistency of their effects in space and time, and an understanding of factors that influence patterns of aggregation and foraging.

In this study we present the results of an experimental manipulation of the density of sea urchins (Paracentrotus lividus Lam. and Arbacia lixula L.) on shallow subtidal reefs on the west coast of Italy (western Mediterranean). These species are the most common herbivorous echinoids in the Mediterranean and, apparently, they are able to produce and maintain patches of barren habitat similar to those described for other parts of the world (Verlaque \& Nedelec 1983, Verlaque 1984, Fanelli et al. 1994). However, previous studies on the effects of these herbivores in the Mediterranean are mainly correlative, experimental analyses being restricted only to littoral rock pools (Benedetti-Cecchi \& Cinelli 1995, 1996). This evidence is not sufficient to make reliable predictions about the effects of changes in density of these populations and on the spatial and temporal consistency of their effects.

As an attempt to address these issues, we tested some general propositions about the ecological role and ecology of sea urchins in shallow subtidal reefs in the Mediterranean. Specifically, we tested whether (1) sea urchins were responsible for the persistence of patches of bare rock and encrusting corallines in shal- low subtidal habitats, (2) their effects were density dependent, and (3) these effects were consistent in time.

\section{MATERIALS AND METHODS}

This study was done on shallow subtidal reefs along the coast south of Livorno, Italy $\left(43^{\circ} 30^{\prime} \mathrm{N}, 10^{\circ} 20^{\prime} \mathrm{E}\right)$, from December 1994 to July 1996. Two major types of habitat occurred in this region: nearly horizontal substrata almost completely covered by algal turfs, and vertical substrata without erect algae. The algal turfs comprised the geniculate corallines Corallina elongata Ellis et Solander and Haliptilon virgatum (Zanardini) Garbary \& Johansen, the fleshy algae Dictyota dichotoma (Hudson) Lamouroux, Laurencia obtusa (Hudson) Lamouroux and Padina pavonica (L.) Lamouroux, and filamentous algae of the genera Ceramium, Polysiphonia and Sphacelaria. The most common organisms on vertical substrata were encrusting algae of the genera Lithothamnion and Peyssonnelia, the limpets Patella caerulea L. and Patella aspera Roeding, the barnacle Balanus perforatus Bruguière and encrusting bryozoans. The sea urchins Paracentrotus lividus Lam. and Arbacia lixula L. were locally abundant at the site, but occurred mainly on the vertical substrata from about 1 to $5 \mathrm{~m}$ in depth in patches that ranged in size from 10 to $50 \mathrm{~m}^{2}$. Often the urchins aggregated in crevices at the base of the reefs or under boulders, but several individuals could also be found scattered in the patches.

The experiment consisted of manipulation of the density of sea urchins in patches on vertical substrata where they normally occurred. The patches ranged in size from 15 to $20 \mathrm{~m}^{2}$ and were distributed over an area of approximately $1000 \mathrm{~m}^{2}$ in water 2 to $4 \mathrm{~m}$ deep. The extension of these patches was estimated subjectively as 20 to $30 \%$ of that of nearly horizontal surfaces. Three patches were randomly assigned to each of the following 4 densities of sea urchins: (1) $0 \times$ (total removal), (2) $0.5 \times(50 \%$ of the average density found in the unmanipulated patches), (3) $1 \times$ (no manipulation of sea urchins), and (4) $2 \times(200 \%$ of the average density found in the unmanipulated patches). The densities of sea urchins were adjusted every 10 to $20 \mathrm{~d}$. Each time, densities were first estimated from 3 randomly located $0.25 \mathrm{~m}^{2}$ quadrats in each of the 3 unmanipulated patches; the average density was calculated and the density in the $0.5 \times$ and $2 \times$ patches (estimated as for control patches) adjusted accordingly the same day (values found prior to adjustment are shown in the 'Results'). Although this procedure could potentially reduce variability among patches (but this was not the case, see 'Results'), it had the advantage, over the 
alternative of adjusting densities with respect to the original value, of incorporating natural fluctuations in the abundance of sea urchins in the evaluation of their impact on the response populations. Densities were reduced in the $0.5 \times$ patches by removal of the appropriate number of urchins (as determined by the numbers found in control patches) at random, while they were increased in the $2 \times$ patches by translocation of the appropriate number of animals collected randomly from non-experimental areas.

The response of the assemblage to the manipulation of the urchins was assessed by monitoring permanent plots marked within the patches and changes occurring along the margins of the patches. Both methods examined the proposition that sea urchins were necessary for the maintenance of the patches, but tested different predictions about the effects of removing or adding these herbivores. The first approach provided a measure of the effects of grazing on organisms colonizing from the water column (e.g. erect algae) and/or on changes in abundance of resident species (e.g. encrusting corallines). The second approach tested whether urchins could prevent the lateral encroachment of organisms from the borders of the patches and eventually could determine the erosion of patch margins.

Six $20 \times 20 \mathrm{~cm}$ plots were permanently marked in each patch at the beginning of the experiment with small pieces of epoxy putty (Subcoat S, Veneziani). The percent cover of algae and bryozoans and the density of limpets and barnacles were estimated at the beginning of the study by sampling 2 randomly chosen plots in each patch; at that time, the 6 plots in each patch were also randomly assigned to 1 of 3 additional dates of sampling (with 2 replicates each): 6, 12 and 18 mo from start. Percent cover values were determined using visual estimates (Dethier et al. 1993, Benedetti-Cecchi et al. 1996) with the aid of a $20 \times$ $20 \mathrm{~cm}$ acrylic sheet divided into $254 \times 4 \mathrm{~cm}$ subquadrats. In contrast to the other components of the assemblage, the encrusting corallines were sampled only twice, at the beginning of the experiment and after 18 mo. Intermediate dates were not considered because these algae became less visible as other species colonised (particularly the erect algae in the $0 x$ plots). By the end of the experiment, all the erect organisms present in the permanent plots were gently removed and the percent cover of the encrusting corallines estimated as described above. Thus, for these algae, there were 2 dates of sampling with 3 replicates each. Densities of limpets were estimated by counting the number of individuals in the whole plots.

The effects of sea urchins on the margins of the patches were evaluated by measuring the distance from a fixed point in each patch (the corner of a permanent plot) to 6 points along the border, as determined by the presence of a mat of erect algae. These measures were repeated at 6 mo intervals. Angles were randomly selected the first time of sampling.

Differences among treatments were analysed using ANOVA. To determine whether adjusting the density of sea urchins with respect to the average value found at each date in control areas decreased the variance among patches in the $0.5 \times$ and $2 \times$ treatments, we did a 2 -factor ANOVA on variances calculated from the 3 replicate quadrats sampled in each patch at each of 6 randomly selected dates. The factors in this analysis were density (fixed) and time (random), with 3 replicates representing independent estimates of the variance within patches.

The response of algae and invertebrates to the manipulation of sea urchins was tested using a 3-factor ANOVA with density and time (elapsed time) as fixed, orthogonal factors and patches nested in density and orthogonal to time as a random effect. Time could be included as a factor in the analyses because independent plots were sampled during the experiment after 6 , 12 and 18 mo from start (only the initial and final dates were analysed for the encrusting corallines). These particular dates were considered as representative of different stages of colonization, according to the patterns observed in the same assemblage at a higher level on the shore (Benedetti-Cecchi \& Cinelli 1994).

The effects of sea urchins on the margins of the patches were evaluated by analysing the changes in the distance between the fixed points and the borders of the patches, expressed as the percentage of the initial measure for each angle, with a 2-factor ANOVA (with density as a fixed factor and patches within density randomy.

Cochran's C-test (Winer 1971, Underwood 1981) was used before each analysis to check whether variances were homogeneous. When necessary, percent cover values were arcsine or square-root transformed, while densities were log transformed. SNK tests were used to separate means (at $\alpha=0.05$ ) following significant differences among means in the ANOVAs.

\section{RESULTS}

There were no significant differences among densities in the mean abundance of sea urchins in December 1994, at the beginning of the experiment $\left(F_{3,8}=1.1\right.$, $\mathrm{p}>0.4$ i analysis on untransformed data). In contrast, there was considerable variability among replicated patches within densities $\left(F_{8,24}=3.0, p<0.02\right)$. Manual removals/additions allowed the maintenance of the desired density of sea urchins in the experimental 


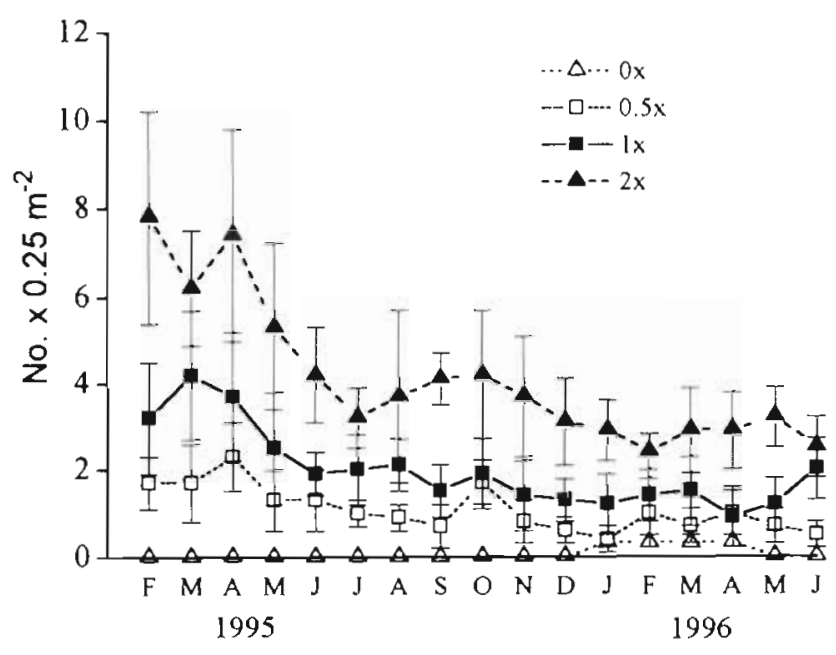

Fig. 1. Paracentrotus lividus and Arbacia Lixula. Mean abundance $( \pm S E, n=9)$ of sea urchins in the different treatments and as a function of time. Data are counts from 3 replicate plots pooled across 3 replicate patches at each time

patches (Fig. 1 ; only 1 date per month is plotted). Natural values ranged from $0.9 \pm 0.7$ to $4.2 \pm 1.5$ individuals per $0.25 \mathrm{~m}^{2}$ (means $\pm \mathrm{SE}, \mathrm{n}=9$ ), with a consistent decrease in abundance after April 1995. The test diameter of these urchins ranged in size from 1.2 to $5.5 \mathrm{~cm}$ (mean $\pm \mathrm{SE}: 3.8 \pm 1.7, \mathrm{n}=40$ ) for Paracentrotus lividus, and from 3.2 to $6.3 \mathrm{~cm}$ (mean $\pm \mathrm{SE}: 4.1 \pm 1.1, \mathrm{n}=40$ ) for Arbacia lixula. The latter represented about $70 \%$ of the total population of sea urchins. Urchins tended to reinvade total removal patches, particularly between January and April 1996, and a greater effort was necessary to maintain their abundance at acceptable levels in this period (Fig. 1). The analysis of variance on variances calculated for each replicate patch in each density (excluding the $0 \times$ treatment) revealed significant effects of density and time, while their interaction was not significant (Density: $F_{2,10}=13.6, \mathrm{p}<0.002$; Time: $F_{5,36}=2.8, \mathrm{p}<0.05 ;$ Density $\times$ Time: $F_{10,36}=0.8$, $\mathrm{p}>0.6$, analysis on log-transformed data). Variances in the $2 \times$ treatment were significantly greater than those in the $1 \times$ and $0.5 \times$ treatments, which did not differ significantly (SNK test). This outcome indicates that variances were positively correlated with the mean density of sea urchins and were independent of the type of manipulation.

Sea urchins had no effect on the encrusting corallines, and the percent cover of these algae did not change between the beginning and end of the experiment (Fig. 2A, Table 1). The lack of significant temporal changes suggested that these forms could also survive when covered by other algae for relatively long periods of time. In contrast, the distribution of the encrusting corallines was heterogeneous in space, as indicated by the significant variability among patches (Table 1).

Sea urchins had a strong impact on the filamentous algae (Fig. 2B). The effect of density was significant, despite the large variability among areas (Table 1, analysis on arcsin-transformed data); the ranking of treatments was: $0 \times>0.5 x>1 \times=2 \times$ (SNK test). There were also temporal changes in the abundance of the filamentous algae, as indicated by the significant effect of time (Table 1); percent cover values at 12 mo were greater than those at 18 and 6 mo, which did not differ significantly (SNK test). In contrast, neither the Time $x$ Density nor the Time $\times$ Patches (D) interactions were significant.

Fleshy algae were abundant only in the complete removal treatments (Fig. 2C, Table 1). There were no significant differences among treatments that retained some sea urchins (SNK test). The distribution of the fleshy algae was consistent in space and time, as indicated by the lack of significant differences among patches, time, and their interaction.

Table 1. ANOVA on the effects of sea urchins and other factors (D: density, $T$ : time) on the abundance of algae and invertebrates Degrees of freedom: Density $=3$, Patches $=8$, Time $=2$ ( 1 for the encrusting corallines), $T \times D=6$ ( 3 for the encrusting corallines), $\mathrm{T} \times$ Patches $(\mathrm{D})=16$ (8 for the encrusting corallines), Residual $=36$ (48 for the encrusting corallines). $" p<0.05, \cdots p<0.01$, $\cdots p<0.001,{ }^{n s}$ not significant

\begin{tabular}{|c|c|c|c|c|c|c|c|c|c|c|c|}
\hline \multirow{2}{*}{ Source of variation } & \multicolumn{2}{|c|}{ Density } & \multicolumn{2}{|c|}{ Patches (D) } & \multicolumn{2}{|c|}{ Time } & \multicolumn{2}{|c|}{$\mathrm{T} \times \mathrm{D}$} & \multicolumn{2}{|c|}{$\mathrm{T} \times$ Patches $(\mathrm{D})$} & \multirow{2}{*}{$\begin{array}{c}\text { Residual } \\
\text { MS }\end{array}$} \\
\hline & MS & $F$ & MS & $F$ & MS & $F$ & MS & $F$ & MS & $F$ & \\
\hline \multicolumn{12}{|l|}{ Algae } \\
\hline Encrusting corallines & 3203.000 & $1.9^{\mathrm{ns}}$ & 1703.000 & $8.2 \cdots$ & 329.400 & $1.6^{\mathrm{ns}}$ & 148.600 & $0.7^{\mathrm{ns}}$ & 205.600 & $1.0^{n s}$ & 207.400 \\
\hline Filamentous algae & 0.716 & $15.4^{\circ}$ & 0.047 & $3.8^{*}$ & 0.070 & $3.8^{\circ}$ & 0.030 & $1.7^{\mathrm{ns}}$ & 0.018 & $1.5^{\mathrm{ns}}$ & 0.012 \\
\hline Fleshy algae & 0.305 & $37.0^{\cdots} \cdot$ & 0.008 & $1.2^{\mathrm{ns}}$ & 0.001 & $0.1^{\text {ns }}$ & 0.012 & $1.4^{\mathrm{ns}}$ & 0.009 & $1.3^{\mathrm{ns}}$ & 0.009 \\
\hline $\begin{array}{l}\text { Peyssonnelia spp. } \\
\text { Invertebrates }\end{array}$ & 0.035 & $0.5^{\mathrm{ns}}$ & 0.068 & $6.2^{\cdots}$ & 0.024 & $0.7^{\mathrm{ns}}$ & 0.019 & $0.6^{\mathrm{ns}}$ & 0.033 & $2.9 \cdot$ & 0.011 \\
\hline Balanus perforatus & 2.386 & $0.3^{\text {ns }}$ & 8.804 & $25.1 \cdots$ & 0.777 & $2.4^{\mathrm{ns}}$ & 0.331 & $1.0^{\mathrm{ns}}$ & 0.331 & $0.9^{\text {ns }}$ & 0.350 \\
\hline Encrusting bryozoans & 0.008 & $1.7^{\mathrm{ns}}$ & 0.005 & $1.5^{n s}$ & 0.011 & $2.4^{\mathrm{ns}}$ & 0.005 & $1.1^{\mathrm{ns}}$ & 0.005 & $1.5^{\mathrm{ns}}$ & 0.003 \\
\hline Patella spp. & 3.111 & $0.7^{\mathrm{ns}}$ & 4.347 & $3.4^{\circ}$ & 4.680 & $2.4^{\mathrm{ns}}$ & 1.792 & $0.9^{\text {ns }}$ & 1.930 & $1.5^{\mathrm{ns}}$ & 1.278 \\
\hline
\end{tabular}


Conversely, the distribution of Peyssonnelia spp. was heterogeneous both in space and time and the Time $\times$ Patch interaction was significant (Fig. 2D, Table 1 , analysis on angular transformed data). Percent cover values decreased after the first 6 mo in 3 of the 12 experimental patches, while no consistent temporal pattern resulted in the remaining areas (SNK tests).

Sea urchins had no impact on the invertebrates (Fig. 3, Table 1, analysis on log-transformed data for Balanus). The distribution of Balanus and Patella was heterogeneous in space, as indicated by the significant differences among patches (Table 1). No other source of variation affected the distribution of these animals significantly, and no significant effect at all was observed for the encrusting bryozoans.

In contrast to the patterns described above for algae and invertebrates, increasing the density of sea urchins had important consequences for the margins of the patches (Fig. 4). In particular, at densities of $2 x$, there was an increase in the mean distance to the borders of the patches (expressed as the percentage of the original value) of more than $50 \%$. Conversely, patches remained stable in the other treatments (Fig. 4). After 12 mo there was a significant effect of density $\left(F_{3,8}=9.0, \mathrm{p}<0.007\right.$; analysis on logtransformed distances), with the mean distance in the $2 \times$ treatment being significantly greater than those of the other treatments (SNK test). Mean distances were homogeneous across patches within densities $\left(F_{8,60}=1.2, \mathrm{p}>0.25\right)$. Similar results were obtained from analyses at 6 and $18 \mathrm{mo}$.
A Encrusting corallines
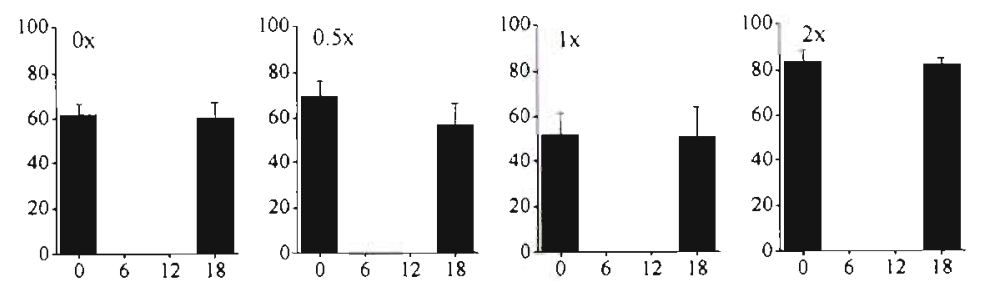

B Filamentous algae
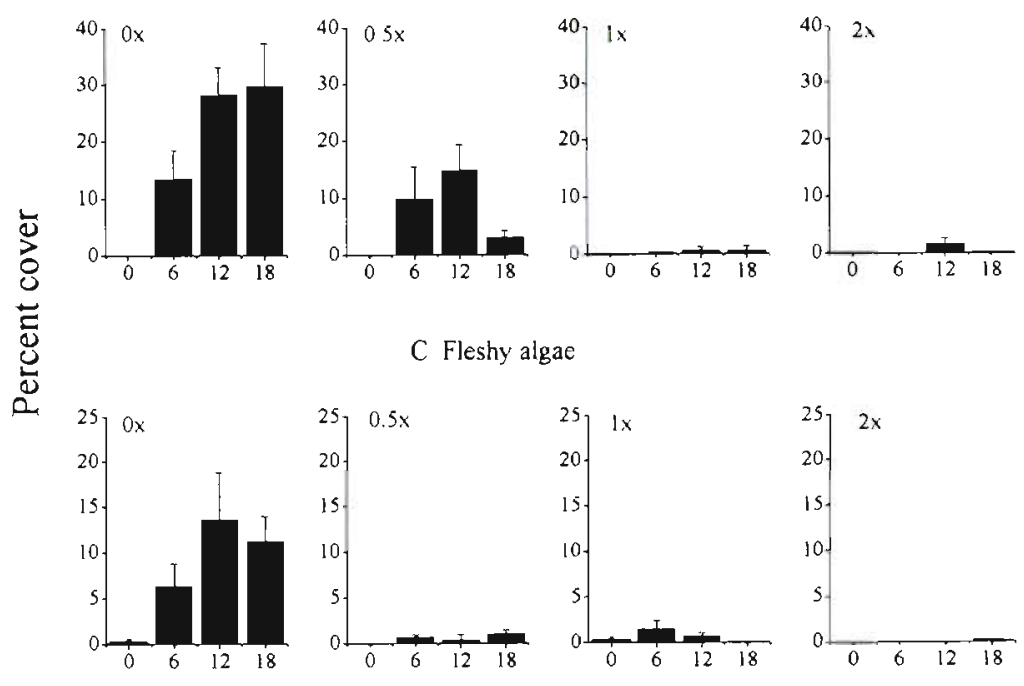

C Fleshy algae
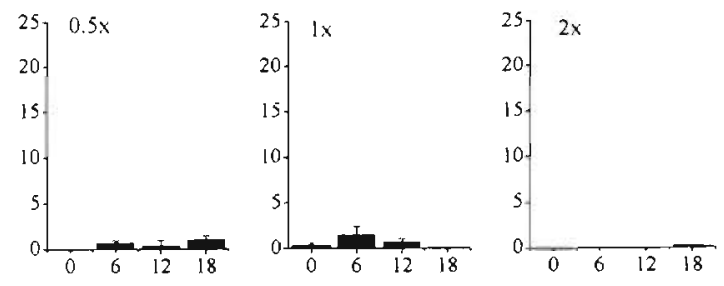

D Peyssonnehaspp
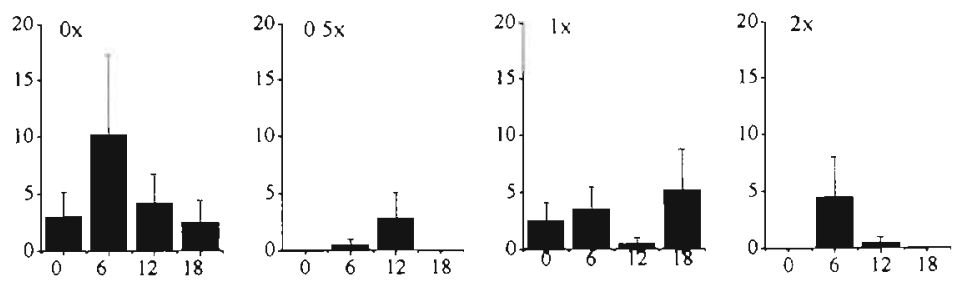

Time (months since initiation)

Fig. 2. Paracentrotus lividus and Arbacia lixula. Effects of different densities of sea urchins on mean algal cover $(+\mathrm{SE}, \mathrm{n}=6$ ) as a function of time. Data are percent cover values from 2 replicate plots pooled across 3 replicate patches at each time

\section{DISCUSSION}

In this study, the removal of sea urchins significantly increased the abundance of the filamentous and fleshy algae, while no effects were observed on the encrusting corallines and Peyssonnelia spp. When present, the effect of grazers was consistent for the 3 dates analysed. The response of the filamentous algae was approximately proportional to the density of sea urchins; the partial removal of grazers produced an effect which was intermediate to that observed in the
$0 \times$ and $1 \times$ treatments. These effects emerged despite the large variability between patches. In contrast, the response of the fleshy algae to the removal of the urchins was non-linear. Only when these grazers were completely removed did the fleshy algae colonize the permanent plots; densities of $50 \%$ of those found in untouched areas were sufficient to keep these plants 'under control'. Notably, grazing was the only relevant factor influencing the abundance of the fleshy algae, highlighting the importance of this process in determining the distribution of these plants. 
A Balanus perforalus
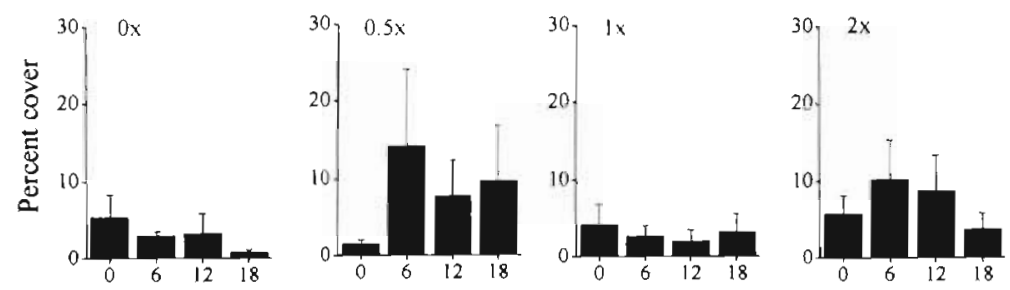

B Encrusting bryozoans
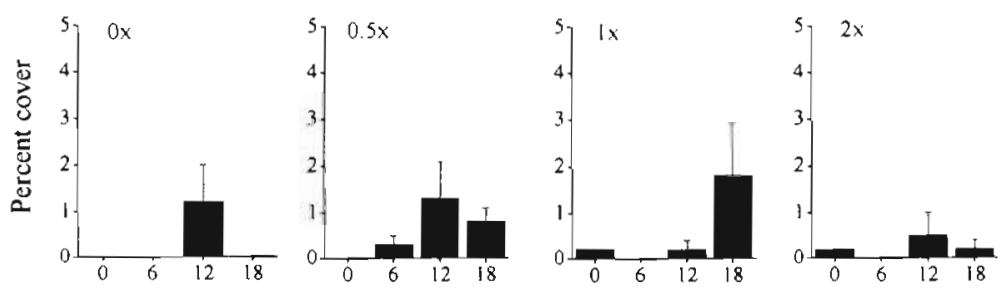

C Patellaspp
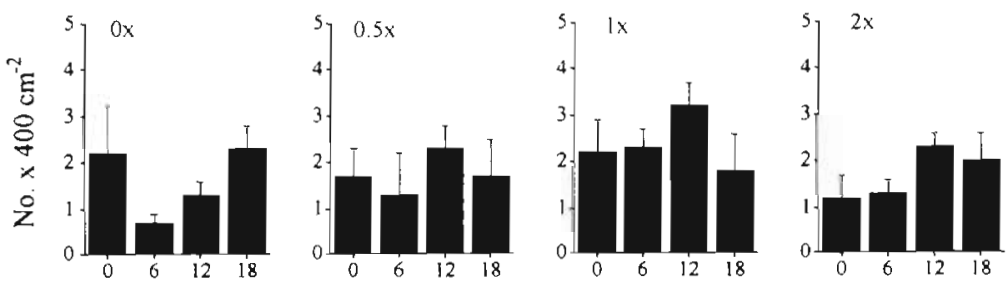

Time (months since initiation)

Fig. 3. Paracentrotus lividus and Arbacia lixula. Effects of different densities of sea urchins on the mean abundance of invertebrates (+ SE, $\mathrm{n}=6$ ) as a function of time. Data are percent cover values (for barnacles and encrusting bryozoans) and counts (for limpets) from 2 replicate plots pooled across 3 replicate patches at each time could also be explained in terms of differences in the rate of recruitment and growth of the 2 groups of algae. This point was also made by Andrew \& Underwood (1993), and additional experiments are required to discriminate among the 2 alternatives.

Removing sea urchins had no effects on the encrusting corallines and Peyssonnelia spp. Several studies have shown that encrusting algae may benefit from the presence of grazers that prevent swamping by erect forms (Paine \& Vadas 1969, Dayton 1975, Paine 1980, Underwood 1980, Steneck 1982, Himmelman et al. 1983, Fletcher 1987). In some of these studies, however, it was not clear whether the encrusting algae were really overgrown and killed or simply were no longer visible. Although the combined cover of the filamentous and fleshy algae was never greater than $50 \%$, some (unquantified) bare rock was also present in the permanent plots and there was considerable overlap in the distribution of the encrusting and erect forms by the end of the experiment (authors' pers. obs,). This suggests that the encrusting corallines and Peyssonnelia spp. could withstand partial colonization of erect plants. Perhaps the portion of the thallus that remained free of epiphytes could acquire and metabolise a sufficient amount of resources to compensate for
Assessing the generality of these results is difficult. Few studies have compared the effects of grazing by sea urchins at different densities (but see Ebert 1977. Valentine \& Heck 1991, Andrew \& Underwood 1993). Andrew \& Underwood (1993) found considerable nonlinearity in the response of some groups of algae and limpets to the manipulation of the sea urchin Centrostephanus rodgersii in New South Wales (Australia). They proposed that individual sea urchins could modify their foraging behaviour to compensate for changes in intra-specific density. This model was based on the principle that when density is reduced, more individuals can forage on food resources of high quality. This predicts that non-linearities should occur more frequently for organisms that are the preferred source of food of the grazers. In the present study, non-linearities were observed for fleshy but not filamentous algae, suggesting that the former were the preferred source of food of the urchins. However, the same pattern

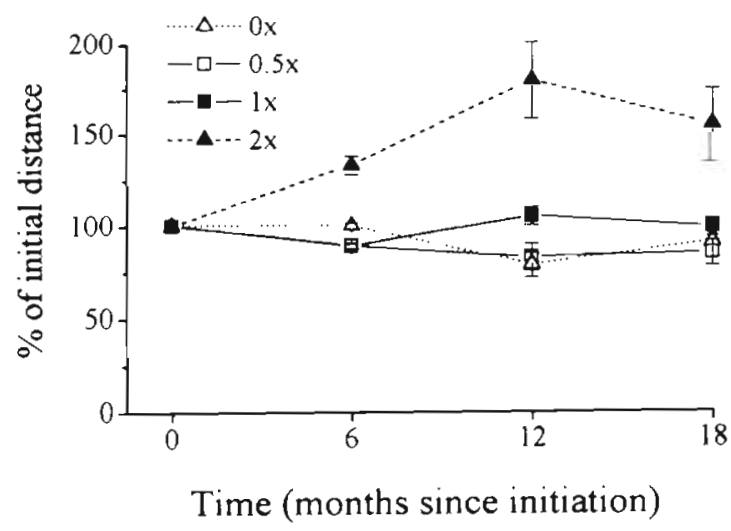

Fig. 4. Paracentrotus lividus and Arbacia lixula. Effects of different densities of sea urchins on the mean distance $( \pm S E, n=$ 18) from a fixed point in the patch to the border, expressed as the percentage of the original value through time. Six replicate measures were pooled across 3 replicate patches at each date 
shading of other parts. Indeed, translocation of nutrients has been described for some encrusting coralline algae (Wetherbee 1979, Steneck 1986) and this may have important ecological consequences, as suggested here. Whether these processes can keep coralline algae alive when overgrown by other organisms for a long time remains to be investigated.

There is evidence from previous studies that sea urchins may have positive indirect effects on the recruitment and/or survival of grazing gastropods and other invertebrates (Sammarco 1980, Ayling 1981, Andrew \& Choat 1982, Himmelman et al. 1983, Fletcher 1987. Andrew \& Underwood 1993). Our results were not consistent with this pattern. There was considerable heterogeneity between patches in the distribution of limpets and barnacles, but no significant effects of sea urchins. This outcome was probably a consequence of the fact that fleshy algae did not saturate space, allowing the persistence of patches of substratum where barnacles, bryozoans and particularly limpets could survive (e.g. Underwood \& Jernakoff 1981). Apparently, limpets at densities of 1 to 3 individuals per $400 \mathrm{~cm}^{2}$ (see Fig. 3) were able to maintain some portions of the substratum free of fleshy algae.

An alternative explanation for the persistence of both the encrusting corallines and invertebrates in the $0 \times$ treatment is that the expected interaction with the erect algae did not occur because the recruitment of these plants was limited. Indeed, the patches of vertical substratum used in this experiment could represent an unsuitable habitat for the erect algae. This is suggested by the fact that nearby areas of horizontal or gently-sloping substrata supported a dense, homogeneous cover of these plants (authors' pers. obs.). Thus, lack of propagules was unlikely, while settlement and early post-settlement events could represent the critical stage for the successful establishment of these plants on vertical substrata.

Doubling the density of sea urchins increased significantly the erosion of the patches. It was relatively easy to maintain such high densities, and emigration from the $2 \times$ patches was negligible (authors' pers. obs.). This suggests that local populations of sea urchins were below the carrying capacity of this type of habitat, and that a natural increase in density would determine an increment of the size of these patches at the expense of the algal turfs. Whether this effect could also occur on horizontal surfaces cannot be assessed from these data and requires additional experiments. The effects of doubling the density of sea urchins, however, must be viewed with caution. Moving the urchins from one patch to another (to create the $2 \times$ treatment) might have altered their foraging behaviour, but there was no simple way to control for this potential artifact. This, in fact, would have required a comparison of the performance of disturbed urchins in experimental patches at $2 \times$ densities with undisturbed urchins in natural $2 \times$ patches, but these did not exist.

The hypothesis that the removal of sea urchins caused changes along the margins of the patches must be rejected on the basis of the experimental results. The complete or partial removal of urchins had no appreciable effects in comparison to untouched areas. These results and the patterns observed in the permanent plots indicate that the main way by which algae colonized was through propagules from the water column, while vegetative growth and encroachment from the margins was of minor importance. The rate of establishment of algae, however, was not sufficient to determine the complete closure of the patches, at least within the 18 mo of the experiment. When performed in other parts of the world, this type of manipulation often caused a change from a barren state to one dominated by algal canopies within 1 to 2 yr (Chapman 1981, Andrew \& Choat 1982, Dayton 1985, Johnson \& Mann 1988; see also discussion in Fletcher 1987). Most of these experiments were done in kelp forests where algal production was high. In contrast, comparatively slower rates of colonization were observed in the turfing habitat examined here. This could be related both to the different life-histories of the species involved (algal turfs vs kelps) and to limitation in recruitment on vertical substrata as discussed earlier. Overall, the results indicate that sea urchins are involved in the maintenance of the patches, but long-term experiments are necessary to determine whether the persistence of this type of habitat can be explained solely in terms of grazing, or if other processes are also involved. Further experiments are also required to assess the relative importance of Paracentrotus lividus and Arbacia lixula which can be expected to exert different effects on benthic macroalgae, the former grazing preferentially over erect algae and the latter on encrusting corallines (Kempf 1962). These experiments are currently in progress and will be reported at a later stage, but preliminary results indicate that $A$. lixula may have significant effects on erect algae, probably because of their relatively high density at these sites.

Acknowledgements. We sincerely thank N. L. Andrew for helpful comments on the manuscript. This work was supported by a MURST $60 \%$ project and by the EU under MAST programme contract MAS3-CT95-0012 (EUROROCK).

\section{LITERATURE CITED}

Andrew NL (1993) Spatial heterogeneity, sea urchin grazing, and habitat structure on reefs in temperate Australia. Ecology 74:292-302

Andrew NL, Choat JH (1982) The influence of predation and conspecific adults on the survivorship of juvenile Evechi- 
nus cloroticus (Echinoidea: Echinometridae). Oecologia 54:80-87

Andrew NL, Underwood AJ (1993) Density-dependent foraging in the sea urchin Centrostephanus rodgersii on shallow subtidal reefs in New South Wales, Australia. Mar Ecol Prog Ser 99:89-98

Ayling AM (1981) The role of biological disturbance in temperate subtidal encrusting communities. Ecology 62:830-847

Benedetti-Cecchi L, Airoldi L, Abbiati M, Cinelli F (1996) Estimating the abundance of benthic invertebrates: a comparison of procedures and variability between observers. Mar Ecol Prog Ser 138:93-101

Benedetti-Cecchi L, Cinelli F (1994) Recovery of patches in an assemblage of geniculate coralline algae: variability at different successional stages. Mar Ecol Prog Ser 110:9-18

Benedetti-Cecchi L, Cinelli F (1995) Habitat heterogeneity, sea urchin grazing and the distribution of algae in littoral rock pools on the west coast of Italy (western Mediterranean). Mar Ecol Prog Ser 126:203-212

Benedetti-Cecchi L, Cinelli F (1996) Patterns of disturbance and recovery in littoral rock pools: nonhierarchical competition and spatial variability in secondary succession. Mar Ecol Prog Ser 135:145-161

Carpenter RC (1984) Predator and population density control of homing behaviour in the Caribbean echinoid Diadema antillarum. Mar Biol 82:101-108

Chapman ARO (1981) Stability of urchin dominated barren grounds following destructive grazing of kelp in St. Margarets Bay, eastern Canada. Mar Biol 62:307-311

Cowen RK, Agegian CR, Foster MS (1982) The maintenance of community structure in a central California giant kelp forest. J Exp Mar Biol Ecol 64:189-201

Dayton PK (1975) Experimental evaluation of ecological dominance in a rocky intertidal algal community. Ecol Monogr 45:137-159

Dayton PK (1985) The structure and regulation of some South American kelp communities. Ecol Monogr 55:447-468

Dean TA, Schroeter SC, Dixon JD (1984) Effects of grazing of two species of sea urchins (Strongylocentrotus franciscanus and Lytechinus amanesus) on recruitment and survival of two species of kelp (Macrocystis pyrifera and Pterigophora californica). Mar Biol 70:301-313

Dethier MN, Graham ES, Cohen S, Tear LM (1993). Visual versus random-point percent cover estimations: 'objective' is not always better. Mar Ecol Prog Ser 110:9-18

Duggins DO (1980) Kelp beds and sea otters: an experimental approach. Ecology 61:447-453

Ebert TA (1977) An experimental analysis of sea urchin dynamic and community interactions on a rocky jetty. J Exp Mar Biol Ecol 27:1-22

Elner RW, Vadas RL (1990) Inference in ecology-the sea urchin phenomenon in the northwestern Atlantic. Am Nat 136:108-125

Fanelli G, Piraino S, Belmonte G, Geraci S, Boero F (1994) Human predation along Apulian rocky coast (SE Italy): desertification caused by Lithophaga lithophaga (Mollusca) fisheries. Mar Ecol Prog Ser 110:1-8

Fletcher WJ (1987) Interactions among Australian sea urchins, gastropods, and algae: effects of experimental removals. Ecol Monogr 57:89-109

Hagen NT (1995) Recurrent destructive grazing of successionally immature kelp forests by green sea urchins in Vestfjorden, Northern Norway. Mar Ecol Prog Ser 123: 95-106

Hawkins SJ, Hartnoll RG (1983) Grazing of intertidal algae by marine invertebrates. Oceanogr Mar Biol Annu Rev 21: $195-282$
Himmelman $J H$, Cardinal A, Bourget E (1983) Community development following removal of urchins, Strongylocentrotus droebachiensis, from the rocky subtidal zone of the St. Lawrence estuary, eastern Canada. Oecologia 59: $27-39$

Johnson CR, Mann KH (1988) Diversity, patterns of adaptation, and stability of Nova Scotian kelp beds. Ecol Monogr 58: $129-154$

Kempf M (1962) Recherches d'écologie comparée sur Paracentrotus lividus (Lmk.) et Arbacia lixula (L.). Rec Trav Stn Mar Endoume Fac Sci Mars 25:47-116.

Lawrence JM (1975) On the relationships between marine plants and sea urchins. Oceanogr Mar Biol Annu Rev 13: 213-286

Paine RT (1980) Food webs: linkage, interaction strength and community infrastructure. The Third Tansley lecture. J Anim Ecol 49:667-685

Paine RT, Vadas RL (1969) The effects of grazing by sea urchins, Strongylocentrotus spp., on benthic algal populations. Limnol Oceanogr 14:710-719

Prince J (1995) Limited effects of the sea urchin Echinometra mathaei (de Blainville) on the recruitment of benthic algae and macroinvertebrates into intertidal rock platforms at Rottnest Island, Western Australia. J Exp Mar Biol Ecol 186:237-258

Sala E, Zabala M (1996) Fish predation and the structure of the sea urchin Paracentrotus lividus populations in NW Mediterranean. Mar Ecol Prog Ser 140:71-81

Sammarco PW (1980) Diadema and its relationship to coral spat mortality: grazing, competition, and biological disturbance. J Exp Mar Biol Ecol 45:245-272

Scheibling RE, Hamm J (1991) Interactions between sea urchins (Strongylocentrotus droebachiensis) and their predators in field and laboratory experiments. Mar Biol 110:105-116

Sousa WP, Schroeter SC, Gaines SD (1981) Latitudinal variation in intertidal algal community structure: the influence of grazing and vegetative propagation. Oecologia 48 : 297-307

Steneck RS (1982) A limpet-coralline alga association: adaptations and defenses between a selective herbivore and its prey. Ecology 63:507-522

Steneck RS (1986) The ecology of coralline algal crusts: convergent patterns and adaptive strategies. Annu Rev Ecol Syst 17:273-303

Underwood AJ (1980) The effects of grazing by gastropods and physical factors on the upper limits of distribution of intertidal algae. Oecologia 46:201-213

Underwood AJ (1981) Techniques of analysis of variance in experimental marine biology and ecology. Oceanogr Mar Biol Annu Rev 19:513-605

Underwood AJ, Jernakoff P (1981) Effects of interactions between algae and grazing gastropods on the structure of a low shore intertidal algal community. Oecologia 48:221-223

Valentine JF, Heck KL (1991) The role of sea urchin grazing in regulating subtropical seagrass meadows: evidence from field manipulations in the Northern Gulf of Mexico. J Exp Mar Biol Ecol 154:215-230

Vance RR, Schmitt RJ (1979) The effect of predator-avoidance behaviour of the sea urchin Centrostephanus coronatus, on the breadth of its diet. Oecologia 44:21-25

Verlaque M (1984) Biologie des juvéniles de l'oursine herbivore Paracentrotus lividus (Lamark): sélectivité du brutage et impact de l'espèce sur les communautés algales de substrat rocheux en Corse (Méditerranée, France). Bot Mar 27:401-424

Verlaque M, Nedelec H (1983) Biologie de Paracentrotus lividus 
(Lamark) sur substratum rocheux en Corse (Méditerranée, France): alimentation des adultes. Vie Milieu 33:191-202 Wetherbee R (1979) 'Transfer connections': specialized pathways for nutrient translocation in a red alga? Science 204 : $858-859$

Editorial responsibility: Otto Kinne (Editor), Oldendorf/Luhe, Germany
Winer BJ (1971) Statistical principles in experimental design 2nd edn. McGraw-Hill, Kogakusha, Tokyo

Witman JD (1987) Subtidal coexistance: storm, grazing, mutualism, and the zonation of kelp and mussels. Ecol Monogr 57:167-187

Submitted: May 13, 1997; Accepted: December 12, 1997

Proofs received from author(s): February 9, 1998 